\title{
Green infrastructure in oil rich states; Abu Dhabi Emirate-Alain as a case study
}

\author{
Mohamed El Amrousi ${ }^{1, *}$, and Mohamed Elhakeem ${ }^{2}$ \\ ${ }^{1}$ Department of Architecture, Abu Dhabi University, 59911, United Arab Emirates \\ ${ }^{2}$ Department of Civil Engineering, Abu Dhabi University 59911, United Arab Emirates
}

\begin{abstract}
The Abu Dhabi 2030 Vision highlights the importance of Sustainable Design and Green Infrastructure inside the UAE and internationally. Future development plans in Abu Dhabi and Alain developed by the Urban Planning Council-UPC manifest emerging interest in Green Infrastructure and Environmental planning. The development of several landscape projects that integrate water elements such as Jahili Park, Al-Ain Al-Fayada and Sheikh Zayed Desert Learning Centre cement the 2030 vision. In order to understand the future of projects with water canals in Desert Cities it is essential to examine the Alain Oasis and its irrigation system known as falaj, that is similar to historic aqueducts and antecedents in the Islamic world such as Qasr Alhambra in Granada/Spain that also had a complex canalization system. This paper studies emerging projects with water features in Alain, and the water flow system in the falaj canalization system in the Oasis by conducting a hydrologic study to quantify the amounts of water needed to irrigate these green areas and simulate the flow condition in the falaj complex channel system using the 2D-hydrodynamic Finite Element Surface Water Modeling System (FESWMS). This paper aims at giving projection of the amounts of water needed sustainable green infrastructure and will be helpful for the decision makers if they want to repeat this model in the future.
\end{abstract}

\section{Introduction}

The United Arab Emirates has developed its landscape in a desert region to have the largest number of fruit-bearing palm date trees in the Arab World, estimated at more than 16 million trees. Abu Dhabi's hinterland city of Alain takes its name from the Arabic translation of the word Spring or Oasis because it includes vast fresh water reserves in its underground rock foundation. The Oasis in Alain has a falaj canalization system that distributes water through its networks via gravitational slope similar to Roman aqueducts, yet it is not covered therefore a percentage of its water evaporates while irrigating palm tree plantations. Alain's complex falaj canalization system is supplied by ground water via submersible pumps between rock formations in Buraimi region, a shared borderland region between the United Arab Emirates and Oman. The Falaj Alaini and falaj Daoudi are the main water supply systems for the Palm Oasis located in the Desert city of Alain, hence they represent a valuable reserve water resource of symbolic and cultural value for the community. In the Arab world fruit bearing gardens "bustan" have a prominent position in history because of their association with paradisiacal metaphors in the Quran and have been described in texts, and depicted in miniature paintings and mosaic panels. Alain city includes many fruit bearing gardens interwoven within its urban fabric. Following the unification of the United Arab Emirates in 1971 urban development of Desert cities such as Alain aimed to attract tribes to the city through offering them large land plots to construct houses for extended families and establishing a national university in 1976 titled the United

* Mohamed El Amrousi: Mohamed.amrousi@adu.ac.ae 
Arab Emirates University (UAEU). Decrees by the founder of the modern Nation Sheikh Zayed bin Sultan Al Nahyan aimed to develop Alain into a Garden City in a challenging desert environment interpreted the planning of the city as a modern city with the Oasis in the center of the downtown area and retained a few traditional adobe forts and residences while the rest of the city expanded horizontally to include modern buildings designed to respect the socio-cultural and environmental criteria of the region such as UAE University Campus, Tawam Hospital, Oasis Hospital, and the Sheikh Zayed Desert Learning Centre are all landmarks that support the green infrastructure of Alain. Alain horizontal growth supplemented by palm tree farms was supported by a building code that sets the limitation of building heights to 20 meters i.e. Ground floor +4 floors [1].

\section{Green Infrastructure and the Modern City}

The role of the Oasis in the centre of Alain city was crucial in the development of the green infrastructure of the city as a whole and its conservation from unplanned urban sprawl, other Oasis in the Alain such as Al-Qattara Oasis followed a similar plan with its traditional market, Arts and Crafts centre manifest a consistent urban strategy that follows the Abu Dhabi 2030 Vision for the development of green infrastructure in Alain and sustainable buildings in Abu Dhabi. A significant section in the 2030 vision emphasized the importance of sustainable development through guidelines known as 'Estidama', a building program for innovative green standards, other legislations such decrees banning the destruction of trees in favour of urban sprawl supported the growth of Alain as the Garden City of the UAE. The city has a population of 627,000 and aims to grow to 1 million by 2030 which may create a challenge on its water resources, while Alain's urban growth is warranted as part of the development of cities in the UAE, Abu Dhabi's Urban Planning Council (UPC) 2007, aims to improve the quality of life in the city through projects that employ water features such as al-Jahili Park (Figure 1a) and contextualized green infrastructure, therefore management of ground and surface water resources is crucial because historically many cities have been deserted as a result of dilapidation of water resources. The UPC Plans exhibit support for the cohesive development of the Oasis and its integration in the modern city, through increased pedestrian access, shaded walkways and extensive public landscapes. Palm trees Oasis gardens and parks and other open spaces in cities offer attractive settings for outdoor recreation that are important for residents' satisfaction with their living environment [2].

Traditional Arab urban enclaves and cities have overtime responded to the harsh Desert climatic conditions and scarce water resources by developing dense urban fabrics, with narrow shaded pedestrian pathways, and adobe courtyard houses with thick walls to protect its inhabitants from the heat. Small windows, and niches were both functional and aesthetic and protected socio-cultural values of Islamic and tribal communities. This is best manifested by the Nizwa Fort and its surrounding buildings that intertwine with the palm trees. The conservation of a traditional building fabric is evident in Nizwa and provides a more picturesque perception to the visitor as a reflection of environmental/regional architecture, however, it also limits the urban expansion of the city. In Abu Dhabi and Alain development of green infrastructure in conjunction with modern transportation means reflect a different approach than that of Nizwa, it is a green infrastructure plan that addresses planning requirements of the modern city hence it is less picturesque than the image of the traditional Arab city. Planners are therefore challenged to balance between tradition and modernity in the same manner that $19^{\text {th }}$ Century planners were as exemplified by Ebenezer Howard in planning the Garden Cities of To-morrow and Frederick Olmsted's Central Park designs. The creation of green infrastructure and healthy cities warrant community education regarding the importance of green infrastructure is part of the 
community's day-to-day activities and highlighting the significance of creating a healthy city that would preserve resources for future generations.

In Alain the new Sheikh Zayed Desert Learning Centre sets another example of the development of green infrastructure in Abu Dhabi. The building which revisits many of the traditional design elements such as narrow windows on the exterior walls and central courtyard reflects Abu Dhabi's initiatives for innovation and reinterpretation of the past. The massive fort like building UAE's first sustainable building to be awarded the 5 Pearl rating from Estidama. The Sheikh Zayed Desert Learning Centre reduces dependency on mechanical air-conditioning through its form and use of solar power. In addition to its narrow lozenge shaped energy efficient windows, and sand textured walls that emulate its Desert environment. The Centre vital for community education and has created around it vast gardens with Palm tree plantations and a reconstructed falaj system (Figure 1b).
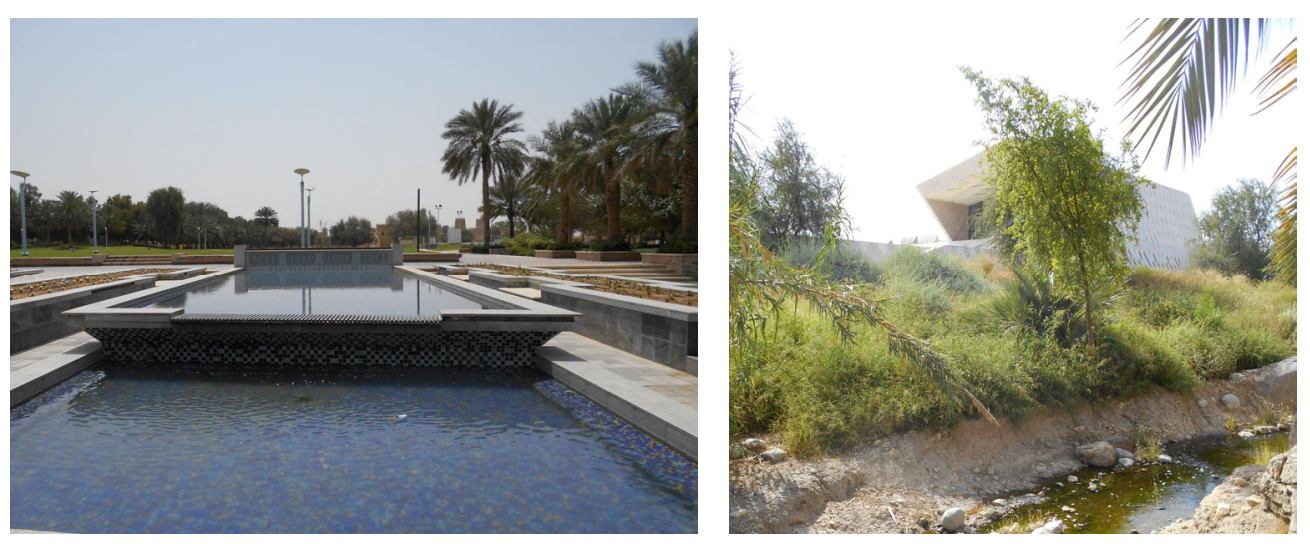

Fig. 1a \& b Al-Jahili Park and Sheikh Zayed Desert Learning Centre-Alain

\section{Developing Alain's urban landscape historical precedents and the living city}

In Abu Dhabi's many projects are developing along water canals such as the new Central Park that includes several kilometres of water bodies along which residential, leisure and entertainment projects are constructed. The main difference between urban developments along seawater canals in Abu Dhabi versus development of projects in Alain is that in first there is abundance in sea water while in the later it is essential to sustain fresh water resources through appropriate management, in the simulation model created in this paper we address the areas water flow in the falaj canalization system in Alain and the highlighting the critical areas, such a study can be expanded on a larger scale to include the study of water flow in the emerging project in Alain Al-Fayda Canal villas in order to sustain them in the future. President studies are also important for understanding the challenges that may face Alain's green infrastructure and urban expansion along water canals. One of the good examples is New York's Central Park that was designed and engineered by Frederick Olmsted, today it sets an example on how water bodies, lakes and canals can reduce the heat island effect and create public space of inclusion in the city. Frederick Olmsted in planning the Central Park in New York advocated for creation of natural landscapes and green areas in cities. At the time such a public park would promote democratic values and improved social life. Even though Olmsted adhered to a naturalistic aesthetic, his draining design, road-making, planting, brush-cutting, and digging artificial 
ponds were all part of the green infrastructure warranted to create such a project [3]. In the Abu Dhabi Central Park which will be developed by Sorouh Investments, water canals are planned to be a dominant site attraction, with 4 kilometres of waterfront/canal side pedestrian Abu Dhabi is thereby constructing an engineered environment as a green Oasis in the modern city. In Alain the opening of Jahili Park located in the downtown area next to Jahili Fort and the recreated Falaj in Sheikh Zayed Desert Learning Centre further cement Abu Dhabi's interest in the development of green infrastructure (Figure 2a \& $2 b$ ). The open garden includes diverse forms of trees and water elements that cascade from geometric basins on several levels. The Park was constructed next to Jahili Fort one of the UAE's historic landmarks and thereby accentuates its visual identity and attracts visitors to it. The introduction of new landscape areas in the city juxtapose modernity and tradition since reconstructing the past as in the case of Nizwa was not park of the planning scheme on the contrary green infrastructure within a contemporary context aimed to complement the city via the creation of lungs in the Downtown area that reduce pollution resulting from exhaust of cars. Similar to Sheikh Zayed learning Centre Jahili Park was planned to increase community awareness of the importance of plants and green spaces and their role in the protection of environment. Here, green infrastructure interventions such as vegetated walls, in addition to the preservation of palm trees and parks mitigate extreme urban heat islands from rising temperature associated with climate change especially in a hot dry climate present in the UAE and the region. Ebenezer Howard in his book the Garden Cities of To-morrow published in 1898, highlights the problems of London as a metropolis that was in need of resolutions for its transformation into a liveable city capable of producing health societies [4]. He proposed a concentric circles diagram that reduces the density of the city centre and sets within its centre a large garden surrounded by leisure pavilions, he also thereby caps the population growth of his Garden Cities by creating a series of small cities that would be interconnected by a railway as public transport. Howard attempts to offer communities a combination of the positive aspects of Cities and Countryside, in that he acknowledges the importance of urban landscape as manifested in his diagrammatic plans that are still valid today. Ideas such as integration of nature into cities translate into green infrastructure and constitute the fundamentals of sustainable urbanism. Howard comprehended the effect of the metropolis in attracting people such as jobs opportunities and leisure facilities and therefore he attempted to combine services of the city and the advantages of the suburban lifestyle such as better communal interaction and larger family oriented living spaces. Setting strict building codes and building height limits for the Downtown area in Alain is a major step to preserve cultural identity of the Downtown area from unplanned urban sprawl and protect the Gold market and the Oasis. Development plans of the existing area of the Downtown and the Oasis display awareness of the importance of landscape and visual connectivity between the Gold Market and the Oasis through the integration of more public spaces development of clusters that take into consideration the sociability and the UAE's cultural values [5]. Similar to Ebenezer Howard's Garden City ideology to connect between the Country Sides with its landscape to Cities via public transport, Alain's development plans exhibit connectivity through green corridors that connect between the edges of the Oasis and the Downtown area. Furthermore, through the construction of a new cultural complex, will enhance the presence of the Oasis similar to the visual connectivity between Jahili Park and Al-Jahili Fort. The concept of transforming urban centres and large metropolises from heterotopias to spaces of inclusion and healthy cities has constantly been a challenge to urban planners and landscape designers. 

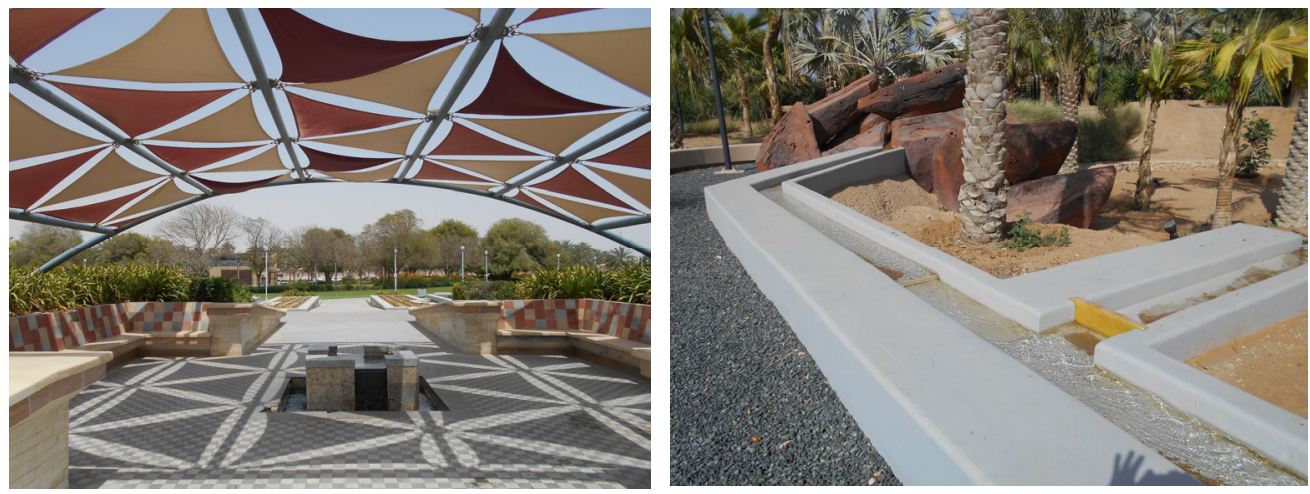

Fig. 2a \& b Al-Jahli Park, and Falaj Garden in Sheikh Zayed Learning Center

The creation of gardens and landscapes in association with urban settings have always been an essential part of planning for better cities, the Shalimar Gardens in Lahore designed in the $17^{\text {th }}$ century employed water elements as an essential part of their composition. Viewing pavilions constructed amidst water ponds and along them further consolidates the importance of water as an essential element in landscape. In Arab world two of the best known examples to us are Madinat al-Zahra on the outskirts of Cordoba and Qasr Alhambra in Granada/Spain. Both cities although several centuries apart can be viewed as examples of Islamic Garden cities that incorporated fruit bearing gardens, open views of landscapes, pavilions and water fountains. Water features in Islamic gardens had many functions from agricultural to aesthetic for example mirroring the formal elements of the irrigated agricultural landscape. The pleasure garden displays the most important formal elements of the irrigated, cultivated landscape: the grid of garden beds where plants are organized and tended, shallow channels for the transport of water, and pools for water storage. They were supported by a complex hydraulic system of falaj supplied by aqueducts. In Madinat al-Zahra landscape was designed based on geometry and symmetry the governed the relationship between buildings and open spaces. This is manifested in reception halls, administrative and government offices, gardens, barracks, residences, and baths. The buildings of Madinat al-Zahra were built on large, stepped terraces were formulated carefully to direct viewers in shaded pavilions to water pools and landscape [6]. In Qasr Alhambra in Cordoba water was used extensively in the exterior landscape and within the bathhouses of palatial complexes. The canalization system allowed water to be elevated to the top (without an electromechanical system) then channelled through the canalization systems with multiple divisions that allowed it to be used in the fountains of the Palace, its canals and then cascaded to the fruit bearing Gardens of the Generalife, via a system of cisterns that made the development of Alhambra gardens and agricultural landscapes around it in the city below it possible. As outlined by Nasser Rabbat the effect achieved by the manipulation of water was certainly intentional as manifested by the Fountain of the Lions were water canals form links between the Gardens and the rest of the palatial city [7]. In Alhambra water was used as an essential resource and also as a method of climate controlling and as an aesthetic element, here Roman aqueducts must be acknowledged as fine examples of water resource management, the role of repair and maintenance must have been critical for a proper operation of the aqueduct system as well as the quality of the waters [8]. 


\section{Alain's Oasis and the falaj, application of the Water Modeling System}

Downtown Alain has the largest Oasis area in and urban setting in the UAE (Figure 3). The preservation of the Oasis and its falaj water system is essential because of declining groundwater its replacement by artificial recharge of groundwater from TSE and desalinated irrigation water which is now widely used to keep the garden city of Al Ain green. The falaj in the Oasis is largely supplemented from pumped groundwater from support wells and piped desalinated water from the relatively new Qidfa desalination plant in Al Fujairah [9].
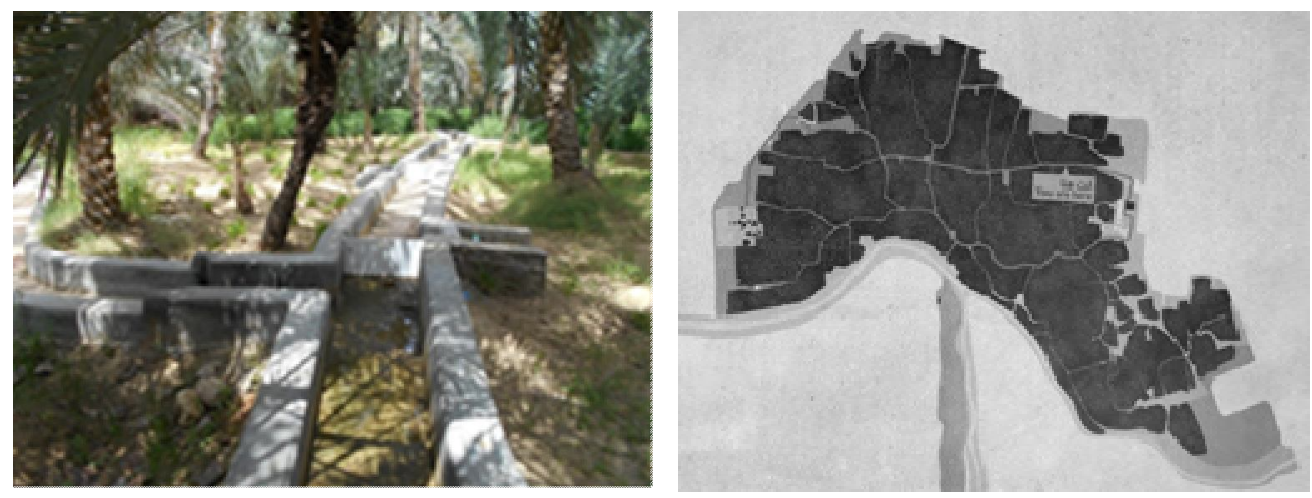

Fig. 3 Alain Oasis falaj irrigation system

Due to the complex landscape geometry of of Falaj Al Ain (Figure 4) irrigation system (canals), the 2D Finite Element Surface Water Modeling System (FESWMS) is used to investigate the flow pattern in the cannels. FESWMS is part of the commercially available Surface water Modeling System (SMS) package version 12.2 Graphical Interface that combines a series of hydrodynamic/ sediment codes [10].

FESWMS solves the differential forms of the continuity and the momentum equations in the stream wise and transverse directions using the Galerkin method of weighted residuals, providing water depth and depth-averaged velocity magnitude in $\mathrm{x}$ and $\mathrm{y}$ directions at each node in the grid [11]. The governing equations are written in the conservative form hence, the momentum is conserved along the streamline and the model is capable of capturing shock effects [12]. The conservative form was chosen because of its robustness in solving critical and transcritical flow fields under both low and high flow conditions by allowing dry-elements to exist within the computational mesh [12].

FESWMS solves the following equations simultaneously:

$$
\frac{\partial z_{w}}{\partial t}+\frac{\partial q_{1}}{\partial x}+\frac{\partial q_{2}}{\partial y}-q_{m}=0
$$




$$
\begin{aligned}
& \frac{\partial q_{1}}{\partial t}+\frac{\partial}{\partial x}\left(\frac{q_{1}^{2}}{d}+\frac{1}{2} g d^{2}\right)+\frac{\partial}{\partial y}\left(\frac{q_{1} q_{2}}{d}\right)+g d \frac{d z_{b}}{\partial x} \\
& +g n^{2} \frac{q_{1} \sqrt{q_{1}^{2}+q_{2}^{2}}}{d^{7 / 3}} \sqrt{1+\left(\frac{\partial z_{b}}{\partial x}\right)^{2}+\left(\frac{\partial z_{b}}{\partial y}\right)^{2}} \\
& -2 d \varepsilon_{x x} \frac{\partial^{2} \bar{u}}{\partial x^{2}}-\varepsilon_{x y} \frac{\partial}{\partial y}\left(\frac{\partial \bar{u}}{\partial x}+\frac{\partial \bar{v}}{\partial y}\right)=0 \\
& \frac{\partial q_{2}}{\partial t}+\frac{\partial}{\partial y}\left(\frac{q_{2}^{2}}{d}+\frac{1}{2} g d^{2}\right)+\frac{\partial}{\partial x}\left(\frac{q_{1} q_{2}}{d}\right)+g d \frac{d z_{b}}{\partial y} \\
& +g n^{2} \frac{q_{2} \sqrt{q_{1}^{2}+q_{2}^{2}}}{d^{7 / 3}} \sqrt{1+\left(\frac{\partial z_{b}}{\partial x}\right)^{2}+\left(\frac{\partial z_{b}}{\partial y}\right)^{2}} \\
& -2 d \varepsilon_{y y} \frac{\partial^{2} \bar{v}}{\partial y^{2}}-\varepsilon_{y x} \frac{\partial}{\partial x}\left(\frac{\partial \bar{u}}{\partial x}+\frac{\partial \bar{v}}{\partial y}\right)=0
\end{aligned}
$$

Eq. (1) is the continuity and Eqs. (2) and (3) are the momentum equations in $x$ and $y$ directions, respectively. In the equations, $t$ is time $(\mathrm{s}), d$ is water depth $(\mathrm{m}), \rho$ is water density $\left(\mathrm{kg} / \mathrm{m}^{3}\right), g$ is the acceleration due to gravity $\left(\mathrm{m} / \mathrm{s}^{2}\right), n$ is Manning's coefficient of roughness, $z_{w}$ and $z_{b}$ are water surface elevation and bed elevation above certain datum $(\mathrm{m})$, $q_{1}$ and $q_{2}$ are the unit discharge fluxes $\left(\mathrm{m}^{2} / \mathrm{s}\right)$ defined as $\bar{u}_{d}$ and $\bar{v}_{d}$, respectively, $\bar{u}$ and $\bar{v}(\mathrm{~m} / \mathrm{s})$ are the depth-averaged velocities of an element in the stream wise and transverse directions, respectively, $q_{\mathrm{m}}$ is the resultant inflow or outflow from that element $(\mathrm{m} / \mathrm{s}), v_{x x}$ and $v_{y y}$ are the normal components of the eddy viscosity $\left(\mathrm{m}^{2} / \mathrm{s}\right)$ in the $x$ and $y$ directions, respectively, and $v_{x y}$ and $v_{y x}$ are the shear components of the eddy viscosity $\left(\mathrm{m}^{2} / \mathrm{s}\right)$ applied to the $x-y$ plane.

FESWMS inputs are the Manning's coefficient of roughness $n$, and the eddy viscosity $v$. Model inputs must be assigned correctly to represent the physical processes occurring in the modeled reach and to produce accurate model predictions. Manning's $n$ is an empirical coefficient that accounts for the total flow resistance caused by flow interaction with the boundary [11]. FESWMS utilizes Manning's $n$ to account for momentum loss due to bedshear, which may vary significantly in a stream reach in accordance to bed-bathymetry and roughness. The second input variable used by FESWMS is the eddy viscosity $v$. Eddy viscosity accounts for flow resistance due to the internal shear stresses, or the Reynolds' stresses of the fluid incorporating the added energy dissipation due to turbulence in the flow [13]. Therefore, eddy viscosity is not a physical property of the fluid, but rather a turbulent characteristic of the flow. For isotropic flows in prismatic channels, a single eddy viscosity value is sufficient to describe the turbulence flow characteristics within the modeled reach. Although FESWMS possesses the capability of spatially distributing both Manning's $\mathrm{n}$ and eddy viscosity in the computational mesh, it is common to use averaged values for Manning's $n$ and eddy viscosity. In prismatic channels under uniform flow conditions, an average eddy viscosity value can be assigned to the study reach as a function of depth and bed slope [14]. Figure 4 shows the model simulation for velocity and the flow direction in the irrigation system of Falaj Al Ain. The irrigation system consists of one main canal 
contributing to three other canals (branches) with 19 outlets that are controlled with sluice gates. The canals are made from concrete of rectangular cross-sectional area with a width of $1.0 \mathrm{~m}$ and height of $0.5 \mathrm{~m}$. The Manning's roughness coefficient and eddy viscosity were estimated as 0.025 and $0.05 \mathrm{~m}^{2} / \mathrm{s}$, respectively. The simulation is made under the extreme condition when all the gates are open. Recorded flow depth at the outlets was $0.4 \mathrm{~m}$ and the flow rate at the inlet was $0.25 \mathrm{~m}^{3} / \mathrm{s}$. The simulations show that the velocity is the range of 0.1 to $0.5 \mathrm{~m} / \mathrm{s}$ with higher values in the main canal and lower values in the branches. Recommended minimum velocity in rigid boundary channels should be in the range of 0.2 $\mathrm{m} / \mathrm{s}$ such that sediment is not deposited, aquatic growth is inhibited, and sulphide formation does not occur, while recommended maximum velocity should be in the range of $1.0 \mathrm{~m} / \mathrm{s}$ to avoid high turbulence in the flow [15]. From the model simulation, it can be seen that the velocities are within the accepted range recommended for rigid boundary channels.

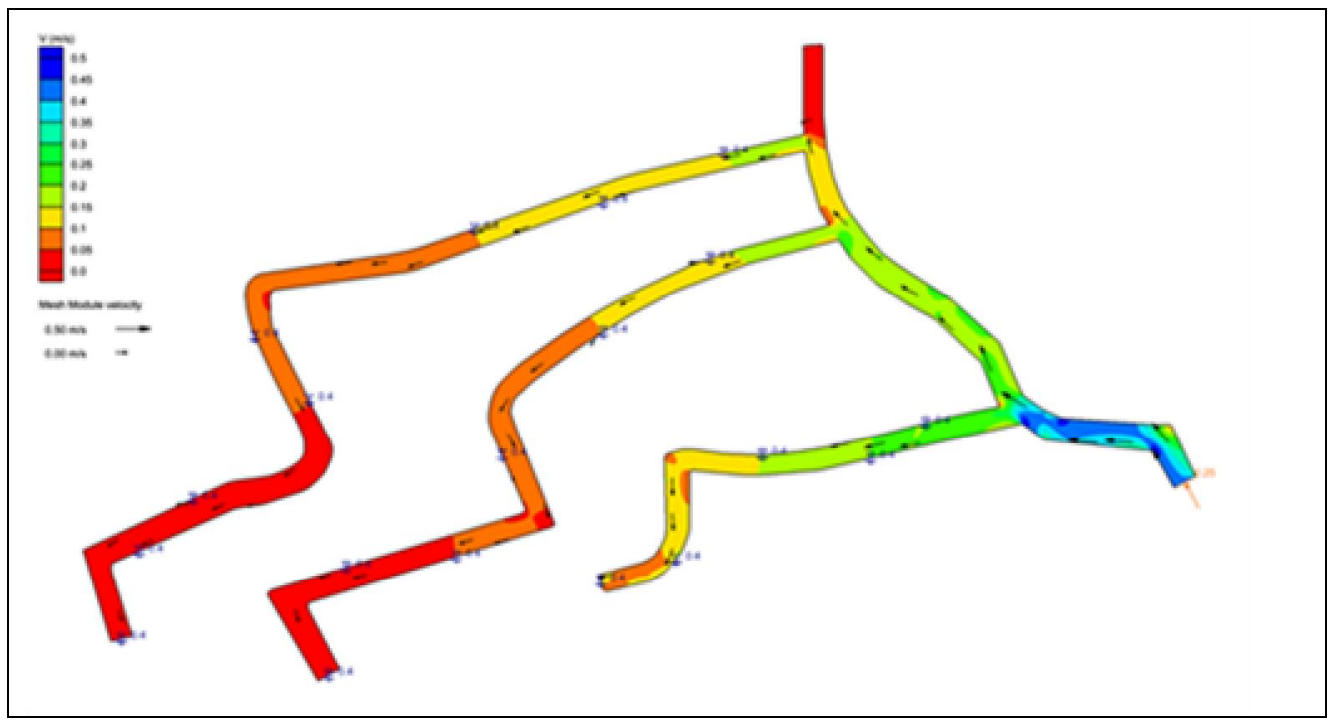

Fig. 4 Simulation of the flow velocity in Alain Oasis falaj irrigation system

\section{Conclusion}

The use of water elements in the urban fabric of the city is essential to create green infrastructure that reduces the heat island effect and creates a health city. Alain is known as the Garden city of the UAE, and its future development through a continuous network of green corridors that emanate from the Oasis to connect the major green areas of the city reinforces Abu Dhabi's plans to create better living spaces for its communities. Linking parks, buildings with courtyards and public outdoor spaces to a continuous network of shaded pedestrian paths pedestrian connectivity to the Downtown area and the Oasis. Water management for irrigation has always been a challenge in Desert cities, today the emergency of community education centres such as the Zayed Desert Learning Centre provide cultural services in addition to education and recreation that further explain to the community how hydraulics and water canalization systems such as the falaj work. Positioning of buildings and their integration within landscape is part of the Abu Dhabi 2030 Vision and it further accentuates how architecture can be used in shaping water to 
create better views of the city, this is exemplified by the investment in the new Abu Dhabi Central Park. While landscape proposals demonstrate how the new development could be integrated with the existing cityscape, it is essential to study precincts especially that many of the Islamic gardens such as those of Qasr Alhambra required consistent maintenance to retain their vitality while many others have been abandoned and perished as a result of water supply shortages. In a city like Abu Dhabi which is emerging in a rapidly homogenizing world, the degree of success of sustaining its green infrastructure needs to be constantly monitored in order to ensure its presence for future generations.

\section{References}

1. Abu Dhabi Urban Planning Council, Abu Dhabi Vision 2030 (2007)

2. O. H. Caspersen, C.C. Konijnendijk, A.S. Olafsson, J. Geografisk Tidsskrift 106, 2 (2006)

3. T.S. Eisenman, J. of Planning History 12, 4 (2013)

4. E. Howard, Garden Cities of To-Morrow (London, 1902)

5. M.A. Benedict, E. McMahon, Green Infrastructure: Linking Landscapes and Communities (Washington, DC: Island Press, 2006)

6. D. F. Ruggles, F., Humanities Research Group 12, (2003)

7. N. Rabbat, Journal of the Islamic Environmental Design Research Centre 2, (1985)

8. H. Chanson, Hydraulic Engineering and Roman Aqueducts: Modern Perspectives, JIA 4, (2015)

9. M. Brook, H. Al Houqani, Current status of Aflaj in the Al Ain area United Arab Emirates (2006)

10. D. Froelich, User's Manual for FESWMS, Release 3 (2002)

11. D.M. Hicks, P.D. Mason, Roughness Characteristics of New Zealand Rivers (New Zealand DSIR Marine and Freshwater Resources Survey, Wellington, NZ, 1991)

12. H.M. Chaudhry, Open Channel Flow (Springer, New York, 2008)

13. A.N. Papanicolaou, R. Hilldale, J. Eng. Mech. 128, 9 (2002)

14. D.R. Richards, Proc. 1990 National Conf. Hydraulics Engineering (ASCE, Reston, VA., 1990)

15. L.R. Mays, Hydraulic Design Handbook (McGraw-Hill, New York, 1999) 